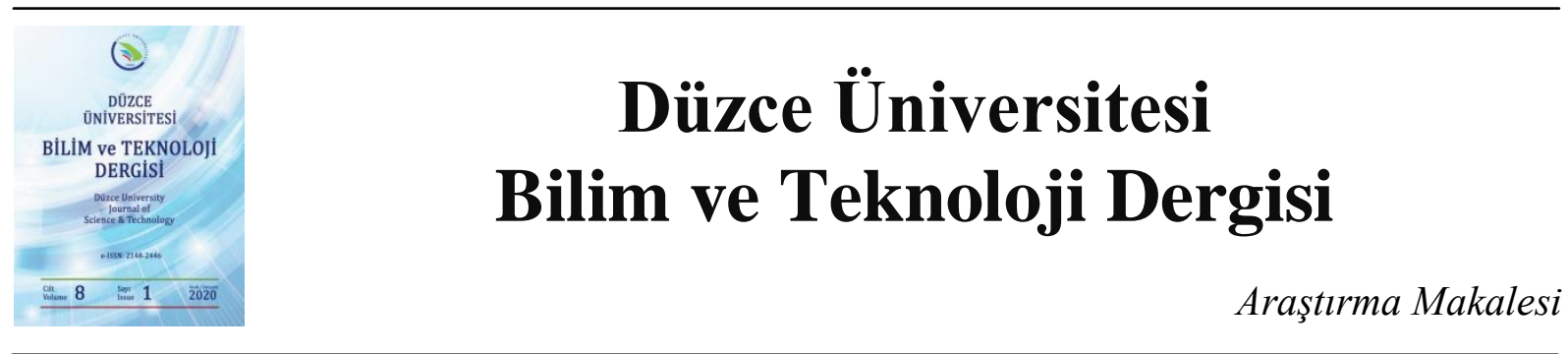

\section{Quercus L. Cinsine Ait Türlerde Kloroplast DNA'ya Ait psbA-trnH IGS Bölgesinin Kullanılarak Filogenetik İlișkilerin Değerlendirilmesi}

\author{
Aykut YILMAZ ${ }^{\mathrm{a}, *}$ \\ ${ }^{a}$ Moleküler Biyoloji ve Genetik Bölümü, Fen Edebiyat Fakültesi, Uşak Üniversitesi, Uşak, TÜRKIYYE \\ * Sorumlu yazarın e-posta adresi: aykutyilmaza@ gmail.com
}

DOI: 10.29130/dubited.637842

\begin{abstract}
ÖZET
Kloroplast genoma ait psbA-trnH IGS bölgesi, en fazla nükleotid dizi farkl1lığı içeren bölgelerden biri olmasından dolayı barkodlama amacı ile bitkilerde sıklıkla kullanılan bölgelerden biridir. Bu amaçla meşelerde var olan taksonomik problemlerin çözümüne katkı sağlamak ve türler arasındaki filogenetik ilişkileri değerlendirmek adına bu bölge bu çalışmada tercih edilmiştir. İlk olarak psbA-trnH IGS bölgesine ait sekans bilgisi analizler için NCBI'den sağlanılmıştır. Daha sonra bu sekanslar hizalandırılmış ve varyasyon gösteren bölgeler için bir bazın diğerine değişim oranları, transisyon/transversiyon oranları, baz frekansları gibi analizler MEGA X programı kullanılarak yapılmışıı. Son olarak, türlerin birbirleri ile olan filogenetik ilişkilerini değerlendirmek adına Neighbor-joining dendrogram hazırlanmış ve analiz edilmiştir. Bu bölgenin meşe türlerinin seksiyonel ayrımı için yeterli varyasyona sahip olmasına karşın, tür ayrımında ve tanımlamasında sekans varyasyonlarının yetersiz kaldığı görülmüştür. Çalışmanın sonucu olarak psbA-trnH IGS sekansının meşelerde barkodlama amacı ile tek başına yetersiz olduğu, bununla birlikte farklı barkodlama bölgeleri ile kullanımının fayda sağlayacağı önerilmektedir.
\end{abstract}

Anahtar Kelimeler: psbA-trnH IGS, NCBI, MEGA X, Transisyon/transversiyon, Neighbor-joining dendrogram, Barkodlama

\section{Evaluation of Phylogenetic Relationships by Using psbA-trnH IGS Region of Chloroplast DNA in the Species of the Genus Quercus L.}

\begin{abstract}
The $p s b A$-trnH IGS region belonging to chloroplast genome is one of the regions which most frequently used in plants for barcoding because of it's nucleotide sequence differences. For this purpose, this region was chosen in this study in order to contribute to the solution of taxonomic problems in oaks and to evaluate phylogenetic relationships between species. Firstly, the sequence information of the $p s b A-t r n H$ IGS region was obtained from NCBI for analysis. Then, these sequences were aligned and analysis for variable sites such as substitution from one base to another base, transition / transversion ratios, and base frequencies were performed using the MEGA X program. Finally, Neighbor-joining dendrogram was prepared and analyzed in order to evaluate the phylogenetic relationships between the species. Although this region has sufficient variation for sectional separation of oak species, sequence variations were found to be insufficient in species separation and identification. As a result of the study, it is suggested that the $p s b A$-trnH IGS sequence alone is insufficient for barcoding in oaks, however it will be beneficial to use it with different barcoding regions together.
\end{abstract}

Keywords: psbA-trnH IGS, NCBI, MEGA X, Transition/transversion, Neighbor-joining dendrogram, Barcoding 


\section{GİRIS}

Fagaceae familyasına ait olan meşeler; Kuzey Yarım Kürede, Amerika, Avrupa, Asya ve Kuzey Afrika'y1 içeren geniş bir bölgede 500'ün üzerinde türle temsil edilmektedirler [1-3]. Quercus L. cinsi, familyanın tür sayısı, geniş coğrafik yayılışı ve yüksek morfolojik varyasyonları ile en iyi bilinen cinsi durumundadır. Fakat bu denli geniş coğrafik yayılış ve tür çeşitliliği beraberinde taksonomik problemleri de cins içerisinde arttırmakta ve bu problemlerin çözümünde yeni çözüm yolları aranmasını zorunlu kılmaktadır. Geniş coğrafik yayılış ve tür çeşitliliğinin yanısıra, meşe türleri arasında ve özelliklede aynı seksiyona ait türlerde sıklıkla görülen hibritleşme davranışı var olan taksonomik problemlerin en büyük sebebini oluşturmaktadır. Meşe türlerinin sınıflandırılmasında en değerli morfolojik karakterler yapraklara aittir. Bunların yetersiz kaldığı durumlarda ise tür tanımlamasında ikincil karakter olarak meyveler değerlendirilmekte ve sıklıkla önerilmektedir. Meşe türlerine ait yaprak ve meyveden sağlanılan birçok karakter ile, bu karakterlerin türlerinin sınıflandırılmasında ve taksonomik ilişkilerinin değerlendirilmesinde önemini gösteren birçok çalışma yapılmış ve bu durumun gerçekliği gösterilmiştir [4-8]. Bununla birlikte bu denli tür çeşitliliğinin fazlalı̆̆ 1 ve beraberinde gelen varyasyonlar, özelliklede hibrit bireylerde gözlenen varyasyonlar, tür tanımlaması için var olan morfolojik karakterler ile tespit edilememekte ve cins içerisinde taksonomik problemleri arttırmaktadır. Bu amaçla birçok sitogenetik ve özellikle PCR temeline dayanan moleküler çalışmalar yapılmakta, özelliklede son dönemlerde sekans analiz tekniklerinin gelişmesi ile hem türü tanımlamak adına yeterince korunmuş ve hem de türler arası ilişkiyi ortaya koyabilecek kadar varyasyon içeren kısa DNA sekans bilgisi temeline dayanan barkodlama çalışmaları hız kazanmıştır [9-12]. DNA barkodlamaya, var olan bu taksonomik problemlerin çözümünün yanısıra, tür çeşitliliğini tayini ve filogenetik ilişkilerinin değerlendirilmesi amacı ilede sıklıkla başvurulmakta ve bu amaçla en uygun bölgeyi bulmak adına çekirdek DNA ve plastid DNA'ya ait bölgeler denenmektedir. Özelliklede hem türü tanımlayacak kadar korunmuş ve var olan nükleotid değişimleri ile türler arası ilişkiyi ortaya koyabilecek sekans farklılıkları içeren plastid DNA sıklıkla tercih edilmektedir. Bitkilerde kloroplast DNA bu amaçlara en uygun bölgelere sahip gibi görünmekle birlikte, hala tüm türleri kapsayan evrensel bir barkodlama bölgesi tespit edilememiştir [11,13,14]. Başka bir deyişle bazı familyalara ait türlerde veya cinslerde çok iyi ayrım yapabilen ve önerilen bir DNA bölgesi, diğer bitki gurupları için taksonomik olarak tür üstü kategorilerde sonuç verebilmektedir [15]. Birçok yayından elde edilen veriler neticesinde ve yaşam barkod konsorsiyumunca bu amaçla en çok tavsiye edilen kloroplast genoma ait bölgeler olarak rbcL, matK, trnK, trnH-psbA, atpB-rbcL, trnT-trnF sayılabilir [14,16,17]. Bu bölgeler, yaşam barkod konsorsiyumunun da önerdiği gibi gen bölgeleri olabildiği gibi, çeşitli bölgelerin kombinasyonu şeklinde de kullanılabilmektedir [17].

Türkiye'de meşeler incelendiğinde, 3 seksiyonda (Quercus, Cerris ve Ilex) 18 tür (25 takson) ile temsil edildiği ve çok geniş bir coğrafik yayılış alanına sahip olduğunu görülmektedir [18]. Bu denli coğrafik yayılış ve tür çeşitliliği Türkiye'de de meşeleri, özellikle Türkiye'nin lokasyonu, jeomorfolojik yapısı ve buna bağlı farklı iklimsel karaktere sahip bölgeleri gibi nedenlerle Dünya'da olduğu gibi problemli kılmaktadır. Ayrıca birçok türün aynı coğrafik bölgede oluşturduğu karışık popülasyonlarda zaten var olan hibridizasyonu arttırmakta ve oluşan varyasyonlar nedeni ile tür sınırlarının çizilmesini zorunlu kılmaktadır. Bunların yanısıra, Türkiye' de $Q$. aucheri, $Q$. vulcanica ve Q. ithaburensis Decne. subsp. macrolepis (Kotschy) Hedge \& Yaltırık gibi endemik taksonların varlığı genetik çeşitliliğin belirlenmesi bakımından cinsi daha da önemli kılmakta ve gen kaynaklarının korunması açısından yapılacak çalışmaları önemli hale getirmektedir.

Belirtilen tüm bu taksonomik problemlerin çözümüne katkı sağlamak ve genetik çeşitliliği belirlemek adına, meşelerde en iyi barkodlama bölgesini bulmak için birçok kloroplast ve çekirdek DNA'ya ait bölgelerin tespit edilip denenmesi ve bu bölgelerin tür ayırım yeteneklerinin ortaya çıkarılması gerekmektedir. Bu çalışmada bu amaçla kloroplast DNA'ya ait psbA-trnH intergenic spacer (IGS) bölgesi barkodlama bölgesi olarak seçilmiş ve Türkiye ile komşusu olan ülkelere ait 17 meşe türünün sekans bilgisi tür ayrım yetenekleri ve filogenetik ilişkilerinin değerlendirilmesi amacı ile kullanılmıştır. 


\section{YÖNTEM}

Çalışmada kloroplast DNA'ya ait psbA-trnH IGS bölgesinin 17 meşe türü için sekans bilgisi National Centre of Biotechnology Information (NCBI)' dan temin edilmiş̧ir [19,20]. Çalışılan türler, türlerin ait olduğu seksiyonlar ve genbank kodları Tablo 1'de gösterilmektedir.

Tablo 1. psbA-trnH IGS bölgesi için çalışmada kullanılan türler, ait olduğu seksiyonlar ve Gen Bank accession numaralart

\begin{tabular}{clll}
\hline Genus & \multicolumn{1}{c}{ Section } & \multicolumn{1}{c}{ Species } & GenBank Acc. No. \\
\hline \multirow{6}{*}{ Quercus } & Q. vulcanica & HE591278 \\
& Quercus & Q. infectoria & HE591305 \\
& Quercus & Q. macranthera & HE591281 \\
& Quercus & Q. robur & HE591285 \\
& Quercus & Q. petraea & HE591314 \\
& Quercus & Q. frainetto & HE591313 \\
& Quercus & Q. pubescens & HE591309 \\
& Quercus & Q. hartwissiana & HE611278 \\
& Quercus & Q. pontica & HE591330 \\
& Cerris & Q. ithaburensis & HE591317 \\
& Cerris & Q. trojana & HE591295 \\
& Cerris & Q. cerris & HE591291 \\
& Cerris & Q. brantii & HE591320 \\
& Cerris & Q. libani & HE591321 \\
& Ilex & Q. ilex & HE591259 \\
& Ilex & Q. coccifera & HE591260 \\
& Ilex & Q. aucheri & HE591315 \\
\hline
\end{tabular}

İlgili barkodlama bölgesi için tercih edilen meşelerin sekansları, Molecular Evolutionary Genetics Analysis (MEGA X) programı kullanılarak ilgili analizleri yapmak adına hizalandırılmıștır. Bir sonraki aşama olarak, psbA-trnH IGS bölgesinin 17 meşe türünde hizalandırılmış DNA'larının varyasyon gösteren bölgeleri belirlenmiş ve Şekil 1 de gösterilmiştir. Ayrıca varyasyonların en büyük sebebi olan bir bazın diğer baza değişim oranları, pürin ve pirimidinler için transisyon/transversiyon oranları, herhangi bir baz gurubuna bakılmaksızın genel transisyon/transversiyon oranları ve çalışılan türlerin ilgili bölge için nükleotid frekansları hesaplanmış ve Tablo 2, 3 ve 4'de gösterilmiştir. Son olarak üzerlerinde bootstrap değerleri belirtilen Neighbour-joining dendrogram, MEGA X programı kullanılarak Şekil 2'de görüldüğü gibi oluşturulmuştur. Filogenetik ilişkileri en doğru şekilde göstermek adına kaçan ve anlamsız data olarak ifade edilen kısımlar programın "complete deletion option" özelliği ile çıkarılmıştır. Sonuç olarak evrimsel analizler 546 nükleotid sekansının toplamında analiz edilmiş ve değerlendirilmiştir. 
Türler

Quercus trojana
Quercus frainetto
Quercus macranthera
Quercus pubescens
Quercus hartwissiana
Quercus vulcanica
Quercus infectoria
Quercus cerris
Quercus robur
Quercus pontica
Quercus ithaburensis
Quercus libani
Quercus brantii
Quercus petraea
Quercus aucheri
Quercus coccifera
Quercus ilex

\begin{tabular}{|c|c|c|c|c|c|c|c|c|c|c|c|}
\hline & & & Sek & a & $\mathbf{B}$ & gis & & & & & \\
\hline & & 1 & 1 & 1 & 2 & 2 & 2 & 2 & 3 & 3 & 4 \\
\hline 5 & 9 & 6 & 6 & 7 & 0 & 4 & 5 & 7 & 1 & 5 & 9 \\
\hline 8 & 7 & 2 & 7 & 2 & 2 & 5 & 7 & 7 & 1 & 2 & 0 \\
\hline $\mathrm{C}$ & $\mathrm{C}$ & $\mathrm{T}$ & $\mathrm{T}$ & $\mathrm{C}$ & $\mathrm{T}$ & $\mathrm{T}$ & $\mathrm{T}$ & $\mathrm{T}$ & $\mathrm{G}$ & A & $\mathrm{G}$ \\
\hline $\mathrm{T}$ & $\mathrm{T}$ & $\cdot$ & $\mathrm{G}$ & A & $\mathrm{G}$ & . & $\mathrm{C}$ & . & r. & . & $\mathrm{T}$ \\
\hline $\mathrm{T}$ & $\mathrm{T}$ & . & . & A & $\mathrm{G}$ & 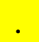 & $\mathrm{C}$ & . & 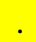 & 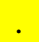 & $\mathrm{T}$ \\
\hline $\mathrm{T}$ & $\mathrm{T}$ & . & . & A & $\cdot$ & 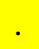 & $\mathrm{C}$ & 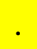 & & . & $\mathrm{T}$ \\
\hline $\mathrm{T}$ & $\mathrm{T}$ & . & . & A & . & 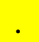 & $\mathrm{C}$ & . & . & . & $\mathrm{T}$ \\
\hline $\mathrm{T}$ & $\mathrm{T}$ & . & . & A & $\mathrm{G}$ & $\mathrm{G}$ & $\mathrm{C}$ & $\cdot$ & . & ${ }^{\circ}$ & $\mathrm{T}$ \\
\hline $\mathrm{T}$ & $\mathrm{T}$ & . & . & A & $\mathrm{G}$ & $\cdot$ & $\mathrm{C}$ & . & . & . & $\mathrm{T}$ \\
\hline & . & . & $e^{\circ}$ & A & . & . & . & . & $\cdot$ & . & . \\
\hline $\mathrm{T}$ & $\mathrm{T}$ & . & 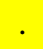 & A & $\mathrm{G}$ & . & $\mathrm{C}$ & . & - & . & $\mathrm{T}$ \\
\hline $\mathrm{T}$ & $\mathrm{T}$ & . & . & A & . & . & $\mathrm{C}$ & . & . & . & $\mathrm{T}$ \\
\hline . & . & . & 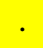 & A & . & . & - & . & . & . & . \\
\hline . & . & . & & A & . & . & . & . & A & . & . \\
\hline & . & . & & A & 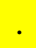 & . & . & . & . & . & . \\
\hline $\mathrm{T}$ & $\mathrm{T}$ & . & . & A & $\mathrm{G}$ & . & $\mathrm{C}$ & $\cdot$ & - & . & $\mathrm{T}$ \\
\hline . & . & $\mathrm{G}$ & . & A & . & . & A & . & . & $\mathrm{G}$ & . \\
\hline & . & $\mathrm{G}$ & & A & & - & A & $\cdot$ & . & $\mathrm{G}$ & - \\
\hline & - & $\mathrm{G}$ & $\mathrm{G}$ & A & & & A & $\mathrm{C}$ & & & \\
\hline
\end{tabular}

Şekil 1. Çalışılan türler ve psbA-trnH IGS bölgesine ait varyasyon gösteren bölgeler (kaçan ve anlamsız data olarak ifade edilen kısımlar çıkarılmıştır)

\section{BULGULAR}

$\mathrm{Bu}$ çalışmanın temel amacı ilk olarak Quercus cinsine ait taksonların filogenetik ilişkilerini anlamak ve taksonomik problemlerin çözümüne katkı sağlamak, ikinci olarak ise barkodlama bölgesi olarak psbA-trnH IGS sekans bilgisinin değerlendirilmesi ve öneminin belirlenmesidir.

$\mathrm{Bu}$ barkodlama bölgesi en fazla nükleotid dizi farklılığ içermesi nedeni ile kloroplast DNA genomunda en sık kullanılan bölgelerden biridir [16,21]. Bununla birlikte bu varyasyonların çoğunlukla insersiyon ve delesyon şeklinde olması, buna bağlı olarak çalışılan türlerde sekans uzunluğundaki farklılıklar, çalışılan türlerde bu bölge için sekans hizalanmasını zorlaştırmaktadır $[16,22,23]$. Çalış1lan meşe türleri için bu bölgedeki varyasyonlar değerlendirildiğinde aynı durum, yani delesyon ve insersiyonlar dan kaynaklı sekans uzunluk farklılıkları bu çalışmada da gözlenmiştir. $\mathrm{Bu}$ sebeple filogenetik ilişkilendirmede anlamlı bilgi elde etmek adına bu bölgeler çıkarılmış ve analizler bu doğrultuda yapıılmıştır.

İlk olarak varyasyon gösteren bölgelerdeki bir bazın diğer bir baza değişim oranları hesaplanmıştır. Tablo 2'de varyasyon gösteren bölgelerdeki baz değişimlerine bakıldığında, en önemli değişimin pirimidinlere ait baz değişimlerinden yani $\mathrm{C}$ ve $\mathrm{T}$ nükleotidlerinin birbirine dönüşümünü ifade eden transisyonel değişimlerden kaynaklandığı görülmektedir. Pürin bazlarına bakıldığında ise buradaki değişimlerin pirimidinlere göre daha dengede olduğu, başka bir deyişle pürinlerin transisyonel ve transversiyonel baz değişimlerinin daha dengede olduğu söylenebilir. Her bir baz gurubu için transisyon/transversiyon oranlarına bakıldığında, pirimidinler için bu oran 3,30 iken, pürinlerde ise 0,86 ile daha dengededir. Herhangi bir baz gurubuna bakılmaksızın varyasyon gösteren bölgelerdeki transisyon/transversiyon oranı ise Tablo 3'de görüldüğü gibi 0,88 'dir.

Tablo 4'de, incelenen meşe taksonlarının psbA-trnH IGS bölgesi için nükleotid frekanslarına bakıldığında, \%70'e yakın bir oranda A ve T bazlarından oluşan bir sekans bilgisine sahip olduğu görülmektedir. 
Tablo 2. psbA-trnH IGS bölgesine ait bir bazın diğerine değişim durumları (koyu bölgeler transisyonelbaz değişimlerini, açık ve italik bölgeler ise transversiyonel baz değişimlerini ifade etmektedir)

\begin{tabular}{ccccc}
\hline & $\mathbf{A}$ & $\mathbf{T}$ & $\mathbf{C}$ & $\mathbf{G}$ \\
\hline $\mathbf{A}$ & - & 7,97 & 4,16 & $\mathbf{2 , 5 8}$ \\
$\mathbf{T}$ & 9,45 & - & $\mathbf{1 3 , 7 7}$ & 2,98 \\
$\mathbf{C}$ & 9,45 & $\mathbf{2 6 , 3 3}$ & - & 2,98 \\
$\mathbf{G}$ & $\mathbf{8 , 1 9}$ & 7,97 & 4,16 & - \\
\hline
\end{tabular}

Tablo 3. psbA-trnH IGS sekansına ait varyasyon gösteren bölgelerdeki pürinler, pirimidinler ve genel transisyon/transversiyon oranlart

\begin{tabular}{lc}
\hline & Transisyon/transversiyon oranı \\
\hline Pürinler & 0,86 \\
Pirimidinler & 3,30 \\
Genel & $\mathbf{0 , 8 8}$ \\
\hline
\end{tabular}

Tablo 4. Her bir baz için psbA-trnH IGS bölgesine ait nükleotid frekansları

\begin{tabular}{cc}
\hline Nükleotid & $\begin{array}{c}\text { Frekans } \\
(\%)\end{array}$ \\
\hline A & 38.47 \\
T/U & 32.44 \\
C & 16.96 \\
G & 12.13 \\
\hline
\end{tabular}

Son olarak 17 Quercus türünün filogenetik ilişkilerini göstermek adına Şekil 2'de gösterildiği gibi Neighbor-Joining (NJ) dendrogram çizilmiştir [24]. Filogenetik ilişkileri gösteren ağaç incelendiğinde, çalışılan türlerin öncelikli olarak 2 guruba ayrıldığ 1 , ilk guruptaki türlerin hepsinin Quercus seksiyonuna ait olduğu, diğer guruptaki türlerin ise diğer iki seksiyon olan Cerris ve Ilex içerisinde ilişkilendirildiği görülmektedir. Kısaca $p s b A$-trnH IGS bölgesine ait sekans bilgisi, türleri birbirleri ile olan ortak özellikleri ve benzerliklerine göre hatasız olarak seksiyonel anlamda ayırmıştır. Fakat türlerin birbirleri ile olan ilişkilerini değerlendirmek adına, başka bir ifadeyle seksiyon içindeki türlerin birbirleri ile olan mesafelerinin değerlendirilmesi adına bazı türler için ayrım yapıyor gibi görünmekle beraber, tam bir tür ayrımı yapamadığı görülmektedir.

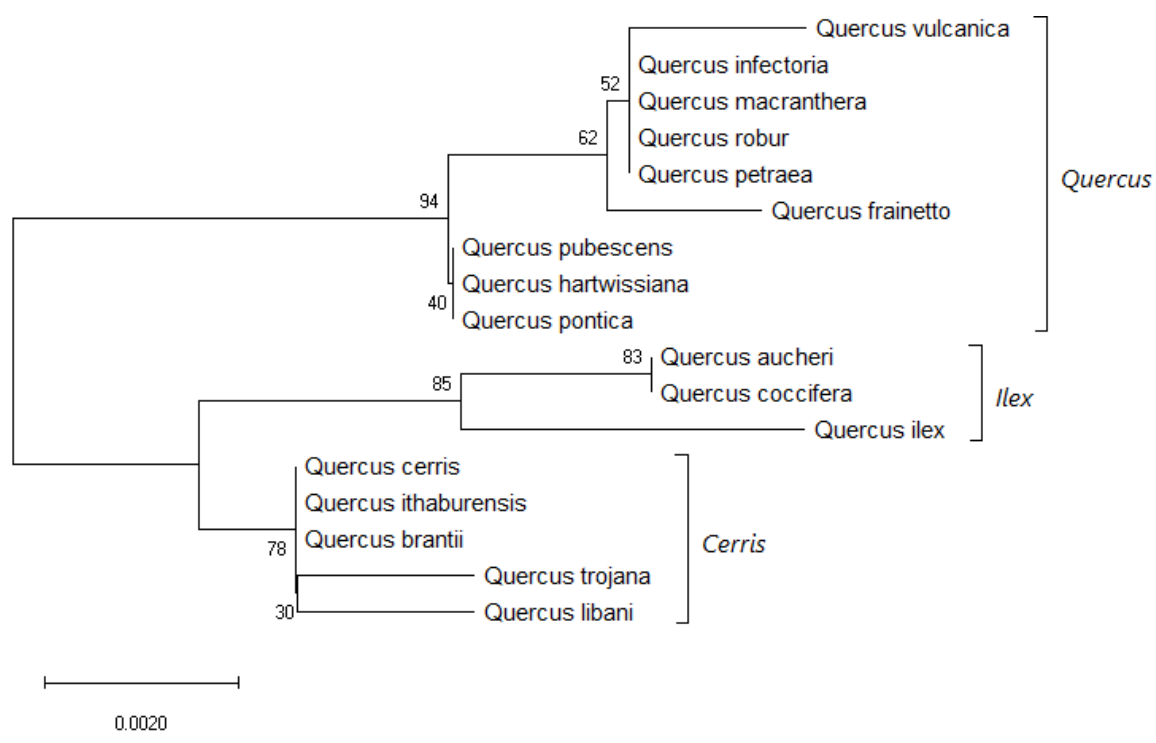

Şekil 2. psbA-trnH IGS bölgesine ait, 17 Quercus türü için Neighbor-Joining dendrogram (Bootstrap değgerleri dendrogram üzerinde gösterilmektedir) 


\section{SONUC}

Günümüzde tür seviyesinde ayrım yapabilecek ve türler arası ilişkilerin değerlendirilebileceği kısa DNA sekansları olarak adlandırılan barkodlama bölgeleri sıklıkla kullanılmakta, özellikle Yaşam Barkot Konsorsiyumunca (CBOL), ifade edilen bu amaçlara en uygun bölgeler olmaları nedeni ile çoğu plastid genoma ait bölgeler var olan problemlerin çözümüne katk1 amacı ile büyük oranda tavsiye edilmektedir $[11,13,25]$.

Bu bölgelerden biri olan psbA-trnH IGS bölgesi, sekans bilgisi temin edilen Quercus türleri üzerine bu amaçla tür ayrım yeteneği ve türler arası ilişkilerin değerlendirilmesinde ki önemini belirlemek amacı ile denenmiştir. 17 meşe türünün sekans bilgisi ilk olarak MEGA X programı kullanılarak hizalandırılmış ve 574 nükleotidlik bir sekans bilgisi elde dilmiştir. Çalışılan meşe türlerinde varyasyon gösteren bölgelerdeki sekans değişimleri incelendiğinde bu durumun yüksek oranda delesyon ve insersiyonlardan kaynaklı olduğu gözlenmiştir. Nükleotid farklılıkları türler arası ilişkileri değerlendirmek adına önemli olmakla birlikte, bu tarz farklılıklardan kaynaklanan sekans uzunluğundaki değişkenlikler, nükleotidlerin hizalandırılmasını zorlaştırmakta ve analiz sonuçlarını bu sebeple olumsuz yönde etkilemektedir. Bu amaçla programda, anlamsız bilgi ve boşluklar olarak görülen bu bölgeler analizde daha etkili sonuç almak adına çıkarılmış ve 546 nükleotidlik bilgiye dayanan analizler bu doğrultuda yapılmıştır. $\mathrm{Bu}$ değişimlerin hangi türlerden kaynaklandığına bakıldığında ise öncelikli olarak Ilex seksiyonuna ait $Q$. coccifera, $Q$. ilex ve $Q$. aucheri'de delesyonlu bölgelerin varlı̆g 1 en fazla görülmüss, daha sonra ise Cerris seksiyonuna ait türlerde ( $Q$. trojana, $Q$. cerris, $Q$. ithaburensis, $Q$. libani ve $Q$. brantii) bu değişimler yüksek oranda görülmüştür. Quercus seksiyonunda ise bu anlamda Türkiye'ye endemik olan ve çok sınırlı bir alanda yayılış gösteren $Q$. vulcanica'da değişimler diğer türler ile kıyaslamada ön plana çıkmıştır.

Türler arası ilişkileri değerlendirmek adına oluşturulan filogenetik ağaç incelendiğinde, türlerin seksiyon temelinde oldukça iyi ayrıldığı, yani varyasyonların türlerin ortak özelliklerine göre ayrımında bu barkodlama bölgesi için anlamlı olduğunu göstermektedir. Ilex seksiyonuna ait türler, Cerris seksiyonuna ait türler ile filogenetik açıdan daha yakın bulunmuş ve buna dişarıdan Quercus seksiyonu dendrogramda bağlanmıştır. Ancak bununla birlikte baz değişimlerini temel alan varyasyonlar dikkate alındığında, Şekil 1'de görüldüğü gibi 12 bölgede değişimler filogenetik analizde değerlendirilmiş ve seksiyonel ayrımda yeterli olsa da, tür seviyesinde bazı türler için ayrım yapmasına karşın genelde yetersiz kaldığı görülmüştür.

Bu durum bu bölgedeki sekans bilgisinin Quercus cinsine ait türler için yüksek oranda korunduğunu, var olan değişimlerin tür üstü kategoriler için, seksiyon bazında çok anlamlı varyasyonlar olduğunu göstermekle beraber, tür düzeyinde bazı ayrımlar görülmekle birlikte genel anlamda yetersiz kaldığı söylenebilir.

Bu çalışmada psbA-trnH IGS bölgesine ait değişimler, Quercus türleri için analiz edilmiş, değişimlerin nedenleri belirlenmiş ve bu barkodlama bölgesinin meşelerde filogenetik ilişkilendirmede ki öneminden bahsedilmiştir. 546 nükleotidlik hizalanmış sekans uzunluğu ile $p s b A$-trnH IGS bölgesi DNA uzunluğu anlamında barkodlama için yeterli olmasına rağmen, baz değişimlerine bağl1 varyasyonlar değerlendirildiğinde çalışılan meşe türleri için oldukça korunmuş bir bölge olduğu ve tür tanımlaması ile birlikte filogenetik ilişkilendirme için CBOL tarafından önerilmesine rağmen yeterli varyasyona sahip olmadığı görülmektedir. Sonuç olarak bu bölgenin meşeler için tek başına iyi bir barkodlama adayı olmadığı, ancak diğer barkodlama bölgeleri ile kullanımının faydalı olabileceği söylenebilir.

TEŞEKKÜR: Bu çalışmada benden yardımını esirgemeyen İbrahim Melih ÖZTÜRKMEN ve Neslihan YILMAZ'a çok teşekkür ederim. 


\section{KAYNAKLAR}

[1] R. Govaerts and D. G. Frodin, "World checklist and bibliography of Fagales (Betulaceae, Corylaceae, Fagaceae and Ticodenraceae,)" Royal Botanic Garden, Great Britain: Kew, 1998.

[2] A. Maryam, R. Fatima and S. Abbas, "Genetic variation among Iranian oaks (Quercus ssp.) using random amplified polymorphic DNA (RAPD) markers," Afr. J. Biotechnol., vol. 11, no. 45, pp. 10291-10296, 2012.

[3] A. Y1lmaz, "Cytotaxonomic study of Quercus L. species from section Quercus in Turkey," Caryologia, vol. 70, no. 2, pp. 141-146, 2017.

[4] A. Borazan and M. T. Babaç, "Morphometric leaf variation in oaks (Quercus) of Bolu, Turkey," Annales Botanici Fennici, vol. 40, pp. 233-242, 2003.

[5] A. Gonzalez-Rodriguez, D. M. Arıs, S. Valencia and K. Oyama, "Morphological and RAPD analysis of hybridization between Quercus affinis and Q. laurina (Fagaceae), two Mexican red oaks," Am. J. Bot., vol. 91, pp. 401-409, 2004.

[6] F. T1lk1 and C. U. Alptekın, "Variation in acorn characteristics in three provenances of Quercus aucheri Jaub. Et Spach and provenance, temperature and storage effects on acorn germination," Seed Sci. Technol., vol. 33, pp. 441-447, 2005.

[7] A. Boratynsk1, K. Marcysıak, A. Lewandowska, A. Jasınska, G. Iszkulo and J. Burczyk, "Differences in leaf morphology between Quercus petraea and $Q$. robur adult and young individuals, "Silva Fenn., vol. 42, pp. 115-124, 2008.

[8] A. Yılmaz, E. Uslu and M. T. Babaç, "Morphological variability of evergreen oaks (Quercus) in Turkey," Bangladesh Journal of Plant Taxonomy, vol. 24, no. 1, pp. 39-47, 2017.

[9] J. Franjic, Z. Liber, Z. Skvorc, M. Idzojtic, R. Sostaric and Z. Stancic, "Morphological and molecular differentiation of the Croation populations of Quercus pubescens (Fagaceae)," Acta Soc. Bot. Pol., vol. 75, pp. 123-130, 2006.

[10] Z. Faltusova, L. Kucera and J. Ovesna, "Genetic diversity of Brassica oleracea var. capitata gene bank accessions assessed by AFLP,” Electron. J. Biotechnol., vol. 14, no. 4, 2011.

[11] R. Piredda, M. C. Simeone, M. Attımonell1, R. Bellarosa and B. Schirone, "Prospects of barcoding the Italian wild dendroflora: oaks reveal severe limitations to tracking species identity," Molecular Ecology Resources, vol. 11, pp. 72-83, 2011.

[12] J. Yang, L. Vazquez, X. Chen, H. Li, H. Zhang, Z. Liu and G. Zhao, "Development of Chloroplast and Nuclear DNA Markers for Chinese Oaks (Quercus Subgenus Quercus) and Assessment of Their Utility as DNA Barcodes," Frontiers in Plant Science, vol. 8, pp. 816, 2017.

[13] D. Selvaraj, R. K. Sarma and R. Sathishkumar, "Phylogenetic analysis of chloroplast matK gene from Zingiberaceae for plant DNA barcoding," Bioinformation, vol. 3, no. 1, pp. 24-27, 2008.

[14] E. Filiz ve İ. Koç, "Bitkilerde DNA barkotları," Afyon Kocatepe Üniversitesi Fen Bilimleri Dergisi, c. 12, ss. 53-57, 2012.

[15] K. Hürkan, "Karasal bitkilerde DNA barkodlama: Bazı DNA barkod bölgelerinin incelenmesi," The International Journal of Innovative Approaches in Science Research, c. 1, s. 1, ss. 57-67, 2017. 
[16] W. J. Kress and D. L. Erickson, "A two-locus global DNA barcode for land plants: The coding rbcL gene complements the non-coding trnH-psbA spacer region," PLoS ONE, vol. 2, no. 6, pp. 508, 2007.

[17] CBOL Plant Working Group, "Plant barcode protocol matK and rbcL, " pp. 599, 2009.

[18] F. Yaltirik, Türkiye meşeleri teşhis kılavuzu, İstanbul, Türkiye: Yenilik Basımevi, 1984.

[19] NCBI. (2019, September 24). GenBank Overview [Online]. Available: www.ncbi.nlm.nih.gov/genbank

[20] R. Piredda, INSDC. DAF, University of Tuscia,Via C. De Lellis, 01100, ITALY, 2011

[21] J. Shaw, E. B. Lickey, E. E. Schilling and R. L. Small, "Comparison of whole chloroplast genome sequences to choose noncoding regions for phylogenetic studies in angiosperms: The tortoise and the hare III," American Journal of Botany, vol. 94, no. 3, pp. 275-288, 2007.

[22] C. C. Chang, H. C. Lin, I. P. Lin, T. Y. Chow, H. H Chen, W. H. Chen and S. M. Chaw, "The chloroplast genome of Phalaenopsisaphrodite (Orchidaceae): Comparative analysis of evolutionary rate with that of grasses and its phylogenetic implications," Molecular Biology and Evolution, vol. 23, no. 2, pp. 279-291, 2006.

[23] M. W. Chase, R. S. Cowan, P. M. Hollingsworth, C. Van Den Berg, S. Madriñán, G. Petersen et al., "A proposal for a standardised protocol to barcode all land plants," Taxon, vol. 56, no. 2, pp. 295-299, 2007.

[24] N. Saitou and M. Nei, "The neighbor-joining method: A new method for reconstructing phylogenetic trees," Molecular Biology and Evolution, vol. 4, pp. 406-425, 1987.

[25] T. Borsch and D. Quandt, "Mutational Dynamics and phylogenetic utility of noncoding chloroplast DNA," Plant Systematics and Evolution, vol. 282, pp. 169-199, 2009. 